\title{
Aprendizagem criativa e educação musical: trajetórias de pesquisa e perspectivas educacionais ${ }^{1}$
}

Viviane Beineke*

\section{Resumo}

O presente artigo discute concepções de criatividade que têm repercutido no campo da educação e da educação musical, analisando diferentes conceitos de criatividade que orientam questionamentos e pesquisas. Partindo de concepções de criatividade que nortearam o ensino nas décadas de 1960 e 1970, são apresentadas tendências emergentes no século XXI, a partir da construção do conceito de aprendizagem criativa. Nessa óptica, o foco é deslocado para as práticas musicais situadas culturalmente, nas quais a criatividade ocorre, pensando que a criatividade das crianças precisa ser promovida dentro de amplas dimensões éticas, salientando as transformações nas relações humanas que os alunos vivenciam e ampliam na aprendizagem criativa, quando participam de uma comunidade de prática musical. Finalizando, argumenta-se que o enfoque da aprendizagem criativa pode indicar uma alternativa possível quando se deseja construir uma educação musical na escola básica que contribua com a formação de pessoas mais sensíveis, solidárias, críticas e transformadoras, quando a criação abre a possibilidade de pensar um mundo melhor.

Palavras-chave: educação musical, criatividade, aprendizagem criativa.

\section{Creative learning and music education: research pathways and educational perspectives}

\begin{abstract}
The present article discusses creativity conceptions which have echoed in education and music education fields, analyzing different creative concepts that guide researches and questions. Starting from creativity conceptions that guided educational tendencies during the 1960's and 1970's, we present emergent tendencies during the 21 st century from the creative learning concept. From this point of view the focus move to musical practices culturally placed where the children's creativity occurs, thinking that this creativity is needed to be promoted inside a wide ethical dimension, stressing the transformations in the human relationships that students experience and expand in the creative learning when they participate in a community musical practice. To conclude, we point out that the creative learning focus could indicate a possible alternative when we wish to build music education in the primary school contributing to educate people to be more sensitive, supportive, critical and transformative using the musical creation as a possibility to think in a better world.
\end{abstract}

Keywords: Music education; Creativity; Creative learning.

* Professora do Curso de Licenciatura em Música e do Programa de Pós-Graduação em Música da Universidade do Estado de Santa Catarina (UDESC). Florianópolis, Santa Catarina, Brasil. 


\section{Viviane Beineke}

\section{Introdução}

A criatividade vem sendo compreendida sob perspectivas muito diferentes ao longo da história. Vista nos tempos antigos como inspiração divina, somente muito tempo depois, durante a era do Romantismo, na Europa do século XIX, a criatividade passou a ser entendida como algo que envolvia as capacidades humanas, tornando-se objeto de estudo nos primórdios da Psicologia (CRAFT, 2011). Como explica Craft (2011), em meados do século XX a criatividade foi analisada sob diversas lentes no campo da Psicologia, perspectivas essas que vêm sendo ampliadas, com contribuições de diferentes campos do conhecimento. No início do século XXI, cresce o reconhecimento de que a criatividade precisa ser compreendida em relação ao contexto cultural no qual se manifesta. Tais trabalhos vêm emoldurando e direcionando estudos nas áreas da educação, da educação musical e, mais especificamente, pesquisas sobre práticas criativas de crianças e jovens em contextos de ensino e de aprendizagem.

$\mathrm{Na}$ área educacional, desde a década de 1970 vem sendo constatada a necessidade de práticas educativas que possibilitem formar cidadãos mais criativos e independentes, preparados para atuar diante das novas demandas e do grande volume de produção de conhecimentos (ALENCAR; FLEITH, 2003). Segundo Alencar e Fleith (2003), alimentados pelas emergentes pesquisas sobre a criatividade, principalmente na área da Psicologia, educadores faziam severas críticas ao sistema educacional vigente, visto como um sistema que, ao invés de desenvolver, estava tolhendo a criatividade dos estudantes. Entretanto, apesar de haver certo consenso sobre a importância do desenvolvimento criativo, tais ideias adquirem sentidos e orientações dissonantes, provocando debates sobre quais são as perspectivas educacionais que impulsionam ou justificam a criatividade na educação.

Atualmente, crescem as abordagens que problematizam o individualismo e a competitividade, amplamente estimulados quando a educação é pautada por critérios econômicos, valorizando a criatividade colaborativa e comunitária (CRAFT, 2011, p. 20). Nessa direção, Craft (2011, p. 33) aponta a importância de discutir como a educação pode tornar-se mais criativa, dentro de amplos valores sociais e éticos. Sob essa óptica, este artigo de estudo teórico foi desenvolvido com o objetivo de discutir possibilidades de entrelaçamento entre concepções de criatividade e implicações no campo da educação musical. Essa discussão é fundamentada em pesquisa mais abrangente, desenvolvida com o objetivo de investigar como as dimensões da aprendizagem criativa se articulam em atividades de composição musical escolar (BEINEKE, 2009)².

\section{Conceitos e definições no campo da criatividade}

A criatividade é compreendida de muitas formas, tanto no senso comum como no campo científico. Analisando o que as pessoas entendem por criatividade, Alencar e Fleith (2003) constatam que ainda predominam muitas 
ideias preconcebidas sobre o tema. Uma delas é que a criatividade é um dom divino destinado a um grupo seleto de indivíduos e que por isso não pode ser ensinada. Outra concepção equivocada de criatividade, citada pelas autoras, é que as pessoas são criativas ou não, quando o que se observa é que existem graus de criatividade.

A crença de que a ideia criativa surge como um toque de mágica também ainda está presente no senso comum, bem como a correlação entre indivíduos muito criativos e o desajustamento ou a loucura, enquanto autores como Amabile (1996) destacam que o indivíduo criativo geralmente é emocionalmente saudável. Alencar e Fleith (2003) apontam ainda a concepção errônea de criatividade como dependente apenas de fatores intrapessoais, sendo subestimadas as contribuições da sociedade no processo criativo.

Não existe consenso sobre o que significa ser criativo. E, segundo Lubart (2007b), a própria definição de criatividade é um tema de pesquisa que está em constante revisão, com debates científicos atuais. Um ponto em comum nas definições de criatividade é que ela envolve sempre a emergência de um produto novo, que pode ser uma ideia ou invenção original (ALENCAR; FLEITH, 2003). Além da necessidade de ser gerado um produto novo, também há certo consenso de que esse produto deverá ter alguma relevância, ser apropriado à sua função. Alencar e Fleith (2003) ressaltam que a criatividade sempre é relativa, pois envolve o julgamento de seus produtos por um número de pessoas, que poderá ou não aceitá-lo como criativo. Quem avalia um produto criativo pode ser uma sociedade, um comitê de pessoas ou um único juiz, mas o nível de criatividade de uma pessoa sempre será avaliado em comparação a outro produto.

Outro ponto de discussão diz respeito aos tipos de criatividade, visando a classificar a abrangência de ideias e produtos criativos. Lubart (2007b) explica que uma produção nova e original, por definição, é aquela que ainda não foi realizada por outras pessoas, mas essa novidade pode ocorrer em diferentes graus: desde um pequeno desvio do que já foi feito até uma grande inovação. Nessa perspectiva, Boden (1999) faz uma distinção entre a criatividade $P$ Psicológica e a criatividade $H$-Histórica, entendendo que uma ideia é $P$-criativa quando ela não poderia ter surgido antes na mente de uma pessoa, não importando quantas vezes outra pessoa já a teve, enquanto uma ideia $H$-criativa é criativa historicamente, o que significa que nenhuma pessoa a teve antes ${ }^{3}$.

Na mesma direção, podem ser apontadas as classificações adotadas por Eysenck (1999), que utiliza os conceitos de novidade privada e a novidade pública para definir graus de criatividade. Com base nesses conceitos, Eysenck distingue a criatividade como um traço pessoal, que leva a pessoa a produzir atos, objetos e fatos de novidade privada, e a criatividade como realização, cujas obras são novidades públicas. Lubart (2007b) utiliza as terminologias criatividade cotidiana e criatividade eminente para designar as produções novas perante o indivíduo ou a humanidade. 
Csikszentmihalyi (1997) diferencia a Criatividade com C maiúsculo, que se refere aos grandes atos e personalidades criativas, da criatividade com $c$ minúsculo, a criatividade cotidiana. Segundo Amabile (1996, p. 82), pode-se identificar um continuum entre a criatividade do dia a dia, das pessoas que resolvem problemas em situações cotidianas de maneira nova, e a criatividade dos grandes gênios, que produzem obras notáveis, que podem transformar campos científicos ou mesmo sociedades. Isso implica assumir que qualquer pessoa pode, em algum grau, ser criativa em algum domínio, daí a compreensão de que uma mesma pessoa pode produzir em diferentes níveis de criatividade.

Gardner (1999) constrói uma definição de criatividade baseando-se em estudos da psicologia cognitiva e do desenvolvimento, bem como aspectos sociais e motivacionais da criação. Segundo o autor (p. 151), "[...] um indivíduo criativo resolve problemas, molda produtos ou levanta novas questões dentro de um campo de uma forma inicialmente considerada incomum, mas depois aceita em pelo menos um grupo cultural". Convém salientar que nessa definição o autor considera produtos da criatividade, com igual importância: a resolução de problemas, a criação de produtos e o levantamento de novas questões. Assim, amplia o conceito em relação às definições que priorizam o produto criativo.

Csikszentmihalyi (1997) define a criatividade como um processo pelo qual as diferentes áreas de conhecimento são transformadas culturalmente. $O$ autor propõe que, em lugar de procurar definir a criatividade, deve-se analisar onde ela está, com a finalidade de compreender como um produto chega a ser considerado criativo e é incorporado à cultura. Este autor ainda argumenta que a criatividade sempre traz implícito um julgamento de valor e que, portanto, um grupo de pessoas vai avaliar e reconhecer o produto ou ideia como criativos. Esses avaliadores não têm um critério objetivo ou padronizado para avaliar o que é criativo, eles se baseiam em experiência passada, treino, bases culturais, valores pessoais e preferências idiossincráticas. Nesse sentido, considerar algo criativo ou não depende sim das qualidades do produto ou ideia, mas sem olvidar o seu efeito sobre pessoas que estão expostas a ele. Por isso, a criatividade é um fenômeno produzido na interação do produtor com a audiência, numa dimensão intersubjetiva ${ }^{4}$.

Em cada uma dessas conceituações, percebe-se uma polarização entre diferentes conceitos de criatividade: Criatividade $\operatorname{com} C$ maiúsculo e criatividade com c minúsculo; criatividade eminente e criatividade cotidiana; criatividade $\mathrm{H}$ - histórica e criatividade $\mathrm{P}$ - psicológica; ou ainda, os conceitos de criatividade como realização ou criatividade como um traço pessoal. O eixo que norteia esses conceitos é o grau que se atribui à realização criativa: até que ponto uma produção criativa é relevante para a sociedade ou tão somente para o indivíduo, ou então, qual é o grau de novidade/originalidade da realização criativa. Dessa forma, Criatividade com C maiúsculo, criatividade eminente, criatividade histórica e criatividade como realização referem-se às produções criativas que introduziram novidades relevantes nos domínios do conhecimento. 
Por outro lado, a criatividade com c minúsculo, criatividade cotidiana, criatividade $P$ - psicológica e criatividade como um traço pessoal são relativas ao indivíduo que produziu algo novo e original somente para ele mesmo. Em cada uma dessas conceituações, percebe-se uma polarização entre o individual e o social: algo é criativo para o indivíduo ou criativo para a sociedade?

$\mathrm{Na}$ área da educação, naturalmente o foco não são as produções criativas que transformam uma área de conhecimento, visto que os estudos se referem a crianças e jovens em processo de aprendizagem (CRAFT, 2005). Daí derivam pesquisas sobre os processos criativos, discutindo o grau de novidade/originalidade da realização criativa de estudantes, bem como os processos que subjazem ao desenvolvimento criativo. Entretanto, cabe observar que tais polarizações conduziram a enfoques em que a criatividade era tida como uma capacidade individual a ser desenvolvida na escola, associada à criatividade com c minúsculo, à criatividade cotidiana ou psicológica. Atualmente se busca superar tal dualidade, com a ampliação do olhar decorrente de perspectivas socioculturais que valorizam enfoques colaborativos de aprendizagem na escola.

Na década de 1990, discutindo a retomada das discussões sobre a importância da criatividade na educação, Craft (2005) considera necessário diferenciar os trabalhos que focalizam o ensino criativo, o ensino para a criatividade e a aprendizagem criativa. $O$ ensino criativo consiste no uso de abordagens imaginativas que tornem a aprendizagem mais interessante e efetiva, focalizando a atuação do professor. O ensino para a criatividade, por outro lado, analisa o desenvolvimento do pensamento criativo dos estudantes, focalizando os alunos. A aprendizagem criativa é um enfoque mais recente, que procura capturar tanto a perspectiva do professor como a dos alunos. Segundo Craft (2005), as pesquisas sobre a criatividade nesse período foram influenciadas pelas abordagens socioculturais e pelos métodos de investigação: em vez de propor estudos com o intuito de medir a criatividade, passaram a enfocar discussões filosóficas sobre a natureza da criatividade e as práticas em sala de aula através de estudos qualitativos.

No início do século XXI, a área de educação introduziu o conceito de aprendizagem criativa (CRAFT, 2005), o qual está situado entre os conceitos de ensino para a criatividade e ensino criativo. Esse conceito, segundo Craft et al. (2008) e Spendlove e Wyse (2008), é um conceito emergente, que demanda pesquisas nos ambientes em que ocorre para que a sua natureza seja mais bem compreendida. Na combinação entre os termos criatividade e aprendizagem é sugerido, de um lado, o envolvimento dos alunos em experimentação, inovação e invenção; e, de outro, é enfatizada a investigação intelectual (CRAFT; CREMIN; BURNARD, 2008). Mudança importante nessa abordagem é a função atribuída ao conhecimento, reconhecendo que a criatividade ocorre dentro de domínios específicos. Em vez de a criatividade ser pensada como um conjunto de habilidades cognitivas ou traços de personalidade, entende-se que as pessoas são criativas dentro de áreas específicas do conhecimento, necessitando 
aprofundar esses conhecimentos para que a criatividade possa emergir. Segundo Feldman (2008), o conceito de criatividade, dentro da expressão aprendizagem criativa, supõe que é a intenção de transformar o mundo de alguma maneira que torna um esforço potencialmente criativo, e se torna criativo quando é julgado como tal. Quanto à aprendizagem, no conceito de aprendizagem criativa, o autor define que ela ocorre dentro de domínios específicos, envolvendo a aquisição de técnicas, habilidades, informação e tecnologia que potencializam o desenvolvimento da criatividade.

$\mathrm{Na}$ esteira dessa discussão, cumpre refletir sobre as concepções educacionais que orientam tais abordagens. Queremos sim desenvolver a criatividade na escola, mas por quê?

\section{O que queremos com a criatividade na escola?}

$\mathrm{Na}$ área educacional, a criatividade é comumente justificada pela necessidade do mercado de trabalho, que exige pessoas criativas, flexíveis e com alta capacidade de adaptação e geração de novas ideias. Nesse enfoque, a escola básica deve formar indivíduos criativos, que possam contribuir de maneira eficaz nas mais diversas profissões visando ao crescimento econômico. Segundo Fonseca (2001, p. 16), considerando os novos desafios da economia global, "Todos os trabalhadores terão de assumir o seu futuro, através duma postura de iniciativa para implementar novas ideias, e terão de adaptar-se às novas condições de produtividade, estas cada vez mais marcadas pela qualidade, pela modernidade e pela competitividade".

Dessa perspectiva, o desafio com o qual a área de educação convive é: como tornar as pessoas mais criativas em um mercado de trabalho altamente especializado e competitivo? Segundo Fonseca (2001), para que as empresas e instituições se mantenham competitivas, são exigidas transformações radicais, complexas e desafiantes, porque "Só nesta base, poderão responder com eficácia e adaptabilidade aos superdesafios do século XXl" (p. 17). De acordo com Ibáñez (2001), essa ideia de criatividade, fundada no princípio da competitividade de mercado, resulta no objetivo da escola básica em detectar e desenvolver potencialidades criativas. Dessa visão de criatividade também decorre a produção de inúmeros manuais e guias que têm o objetivo de desenvolver a criatividade individual e organizacional visando à formação de lideranças e promovendo o sucesso profissional em diferentes áreas ${ }^{5}$.

As justificativas apresentadas por Fonseca (2001) e lbáñez (2001) não condizem com o argumento construído neste trabalho, que está mais próximo dos questionamentos de Barata-Moura (2001), que critica objetivos educacionais orientados por valores materiais, relacionando a perspectiva acima com o "império do efêmero" no qual vivemos. O autor interroga por que a criatividade é entendida como um valor: "Será porque a 'novidade' é requerida em ritmo acelerado para satisfazere reproduzir uma ânsia insuflada de consumo interminável [...]?” (p. 140). 
Craft $(2003,2005)$ também questiona propostas educacionais baseadas em princípios de excelência regidos por critérios econômicos como parte de um discurso universalizado no mundo ocidental. A autora (2005) explica que o desenvolvimento da criatividade na educação pode ser visto como uma resposta às condições da economia global, mas problematiza: até que ponto é desejável sustentar a cultura da moda que dita a necessidade de constante modificação e atualização, estimulando a inovação pela inovação, sem referência à necessidade genuína? Ou o que se pode dizer sobre os valores transmitidos pelo mercado de que aquilo que se deseja é o que se necessita? (CRAFT, 2003, p. 121).

Craft (2003) ainda salienta que não se pode esquecer que a criatividade tem um lado mais obscuro, pois a imaginação humana também é capaz de causar imensas destruições. Para a autora, o desafio é outro: como se pode gerar sistemas que estimulem e celebrem a criatividade dentro de uma perspectiva profundamente humana, encorajando o exame crítico dos valores inerentes às ideias e ações criativas? Craft (2005) defende que a criatividade das crianças precisa ser promovida dentro de amplas dimensões éticas, buscando maneiras de desenvolver a capacidade dos alunos de perceber que as ideias têm consequências que precisam ser examinadas criticamente. Segundo a autora, espera-se que essas sejam questões centrais do educador em qualquer trabaIho criativo. Nessa perspectiva, a criatividade na escola é associada também ao pensamento reflexivo e aos valores que encorajam a construção de posicionamentos críticos, incentivando um pensar socialmente participativo e colaborativo.

Como será visto a seguir, tais ideias têm repercussões na área de educação musical, que vem (re)construindo os fundamentos que orientam as práticas criativas em sala de aula.

\section{Olhares para a criatividade na educação musical}

Um grande corpo de pesquisas sobre a criatividade na educação musical está relacionado aos estudos da Psicologia que focalizam os processos criativos, investigando a sucessão de pensamentos e ações que geram a produção criativa (KRATUS, 1994). As pesquisas de Kratus sobre como os processos criativos se estabelecem em composições de crianças são referência na área, visando a compreender as ações de gerar, desenvolver, testar e julgar ideias musicais. Pesquisas dessa natureza contribuem para a prática em sala de aula porque possibilitam que o professor compreenda os processos de pensamento e construção de significados que orientam a produção musical dos estudantes, podendo auxiliar no planejamento e na ação pedagógica.

O conceito de criatividade psicológica, bastante difundido na área de educação musical, focaliza os processos de aprendizagem das crianças, valorizando suas descobertas e a maneira como elas interpretam e (re)criam conhecimentos. Essa é a abordagem de Tafuri (2006), quando afirma que entende a 
criatividade como um potencial relacionado às propriedades da cognição humana. Concordando com o conceito de criatividade com c minúsculo, a autora relaciona criatividade a desenvolvimento psicológico. Consequentemente, sempre que uma criança inventa algo que é novo para ela, pode-se falar em criatividade.

Esse enfoque tem sustentado modelos educacionais desde as décadas de 60 e 70, propondo o desenvolvimento criativo como estratégia para o desenvolvimento pessoal ou vinculado às áreas artísticas (CRAFT, 2005). Como exemplo dessa abordagem, pode-se situar as propostas de John Paynter, que têm "como alicerce pedagógico os princípios de liberdade, descoberta e individualidade" (MATEIRO, 2011, p. 245). Segundo Cheng (2008), sob a óptica da criatividade psicológica, a autoavaliação é a maneira mais eficiente de avaliar a criatividade, quando as crianças analisam sua produção recente tendo como referência suas realizações anteriores. Na visão da autora, assim se previne o impacto negativo que a comparação e a competitividade entre pares podem ter para a autoestima das crianças.

Cheng (2008) argumenta que não é apropriado avaliar a criatividade na educação escolar considerando apenas critérios pessoais nem considerando somente os critérios amplos do domínio de conhecimento. Essa perspectiva fundamenta-se nos pressupostos da Técnica de Avaliação Consensual (TAC) ${ }^{6}$ de Amabile (1996), baseada no argumento de que um produto ou resposta é criativo à medida que observadores apropriados concordam que ele é criativo. Com base nesse princípio, passou a ser questionado também quem é que pode estabelecer critérios e julgar os produtos criativos dos estudantes. Na área de educação musical, as investigações realizadas por Hickey (2001) e Priest (2001) partem da TAC para perguntar: quem são os "especialistas" ou "juízes apropriados" quando são julgadas composições de crianças? As crianças podem ser avaliadoras confiáveis dos produtos criativos de outras crianças? Também fundamentada na TAC, Cheng (2008) propõe que a avaliação da criatividade seja baseada na comparação entre pares, considerando os critérios das crianças e também os do professor, incluindo a autoavaliação. Dessa forma, a autora acredita que alunos e professores podem negociar seus julgamentos e refletir conjuntamente sobre o que significa ser criativo, encorajando os estudantes a pensarem sobre sua própria aprendizagem.

O olhar para a criatividade das crianças, segundo Burnard (2006), pode ter suas lentes ampliadas quando as relações entre fatores individuais e sociais são entendidas como mediadores de expectativas e concepções sobre as práticas criativas, abordagem apresentada a seguir.

\section{A aprendizagem criativa em comunidades de prática musical}

Burnard (2006) argumenta que as crianças iniciam a vida no convívio familiar e, progressivamente, vão ampliando suas experiências sociais de forma a incluir múltiplas culturas e esferas de influência. Dessa forma, a cultura das crianças vai dilatando-se, em círculos concêntricos cada vez mais amplos, que repre- 
sentam os mundos individuais e sociais da supracultura (dimensão mais abrangente) da criatividade musical de crianças (Figura 1). Como explica a autora,

O desenvolvimento criativo da criança ocorre dentro de várias unidades sociais e culturais, bem como da influência de pais e cuidadores no núcleo familiar, ou na interface dos contextos sociais com amigos e colegas dentro e fora das comunidades escolares e como membros de múltiplas culturas [...]. (BURNARD, 2006, p. 354)

Ampliando o foco para compreender como a criatividade das crianças é mediada culturalmente, são iluminadas as interseções entre a supracultura (tanto das crianças como de modo geral), as subculturas (como idade, gênero, etnia), as microculturas (da sala de aula, da comunidade do coro ou banda de garagem) e as interculturas (que constituem, por exemplo, ouvintes de música popular de massa (BURNARD, 2006, p. 368). Assim, a criatividade musical consiste em atividade contextualizada, compreendida nas dinâmicas entre os diferentes contextos, que incluem os mundos individuais e culturais da criança.

Nessa perspectiva entende-se que a criança pode engajar-se criativamente na música dentro de uma grande variedade de comunidades de prática, como a aula de música na escola, uma banda comunitária, ambientes recreativos, praças e parques, no ambiente familiar e inúmeras outras comunidades musicais nas quais as crianças podem participar (BURNARD, 2006, p. 358) ${ }^{7}$.

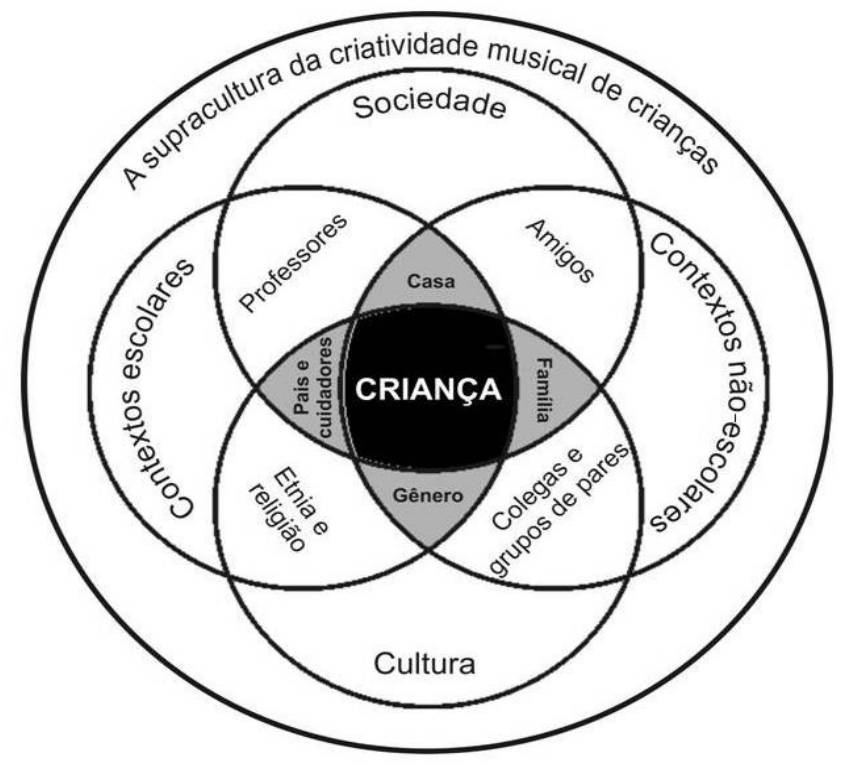

Figura 1 - A supracultura da criatividade musical de crianças Fonte: Burnard, 2006, p. 368. 


\section{Viviane Beineke}

Assim, o fazer musical das crianças é compreendido em relação às práticas musicais a que elas têm acesso, cabendo ao processo educativo ampliar essas possibilidades de acesso e sua compreensão. Na perspectiva da aprendizagem criativa, é necessário considerar que o grupo em sala de aula configura uma comunidade de prática que está se iniciando coletivamente num domínio específico: a música. Segundo Wenger (2008, p. 53), participar de uma comunidade envolve negociar os sentidos das suas práticas, o que implica: um processo ativo e dinâmico construído ao longo do tempo; um mundo de resistência e maleabilidade; a habilidade mútua de afetar e ser afetado; o engajamento de uma multiplicidade de fatores e perspectivas; a produção de novas resoluções para que esses fatores e perspectivas se tornem convergentes; a incompletude dessas resoluções, que podem ser parciais, efêmeras e específicas a cada situação. Dessa maneira, a comunidade em sala de aula estabelece os critérios e participa da validação e da recriação das ideias de música nas suas práticas musicais, em processo intersubjetivo no qual as ideias de música são atualizadas e incorporadas por essa comunidade (BEINEKE, 2009).

$\mathrm{Na}$ aprendizagem criativa, a realização de tarefas de criação colaborativa permite desenvolver e expandir a compreensão e construção de significados pelos alunos. Como observou St. John (2006), fazendo música em conjunto, trocando ideias e transformando os conteúdos propostos pelo professor, as crianças podem descobrir o prazer da expressão musical, porquanto as interações entre os pares influenciam grandemente a qualidade da experiência. Como agentes de sua própria aprendizagem, elas mostram o que pode facilitar sua compreensão; e quando o professor observa e honra suas interpretações, ele valoriza os esforços dos alunos no desenvolvimento de habilidades musicais e na experiência prazerosa do fazer musical coletivo.

Analisando características da interação musical em jogos cantados no contexto informal de parques, Marsh $(1995,2008)$ observa processos de composição em que as crianças colaborativamente transformam e variam textos, música e movimento, claramente influenciadas pela própria interação mútua. A autora observa que as composições são reguladas através de um ciclo interdependente de composição e performance em grupo, num processo cíclico de execução e criação relacionado à tradição das músicas orais. Focalizando a improvisação, Burnard (2002) também constata que as interações entre os alunos na sala de aula são determinantes dos trabalhos produzidos, quando as crianças aprendem coletivamente a transpor seus potenciais individuais, negociando funções e papéis que acontecem dentro e fora da performance.

Essa maneira de compor e improvisar música pode ser relacionada ao que Sawyer (2006) chama de criatividade em grupo. Segundo o autor, a tendência é atribuir a criatividade do grupo a um único participante, em vez de perceber a emergência da dinâmica grupal. Assim como nos jogos cantados citados por Marsh $(1995,2008)$ e nas improvisações de jazz, os processos criativos são regidos por convenções comuns aos participantes, que viabilizam a comunica- 
ção. Sawyer (2006) concorda com Campbell (2006), ao afirmar que as crianças aprendem práticas musicais socializadas informalmente numa comunidade de prática ${ }^{8}$, sua cultura de pares. Nessa perspectiva, pode-se observar um redimensionamento do conceito de processo de composição, porque quando as músicas das crianças são separadas do contexto de produção, o conceito de processo torna-se abstrato e distante das músicas das crianças (YOUNG, 2003).

Nessa abordagem, a meta dos educadores musicais para o desenvolvimento criativo não se resume a técnicas de composição e a transmissão de conhecimentos, mas abrange a criação de comunidades musicais de prática, fundadas nos princípios da criatividade e colaboração musical. Nessas comunidades, estabelecidas no contexto do ensino de música, as atividades em grupo permitem diferentes níveis de participação, acomodando diferentes estilos de aprendizagem e níveis de desenvolvimento. Segundo Sawyer (2006), cada estudante pode participar de maneira significativa em seu próprio nível, e a atividade é organizada de forma que cada nível de participação naturalmente impele a criança para uma crescente apropriação, mestria e participação central. Em uma sala de aula assim organizada, as crianças aprendem muito mais que os mecanismos musicais, aprendem habilidades de interação, como ouvir e responder apropriadamente, a colaborar e a se comunicar em um contexto social.

Em estudo de caso realizado em aulas de música de uma turma da $2^{\text {a }}$ série do Ensino Fundamental com o objetivo de investigar como as dimensões da aprendizagem criativa se articulam em atividades de composição musical no contexto do ensino de música ${ }^{9}$ na escola básica (BEINEKE, 2009), observou-se que as dimensões da aprendizagem criativa se articulam nas atividades de composição em grupo, apresentação e crítica musical das produções dos alunos, em um ciclo que aciona processos de estabilização e desestabilização de ideias de música construídas intersubjetivamente em sala de aula. Nesse trabalho, o conceito de participação das crianças em processos colaborativos de composição musical foi se aproximando da caracterização de uma comunidade de prática musical. Sob essa óptica, a prática musical estabelecida no conjunto de atividades de composição, abrangendo a apresentação e a crítica dos trabaIhos, pode ser entendida como um recurso de coerência na comunidade, que engloba engajamento mútuo, empreendimento conjunto e repertório compartiIhado. Como argumenta Wenger (2008, p. 9), assim pode-se superar a concepção educacional de que o conhecimento consiste em pedaços de informação que são empacotados em unidades de ensino bem desenhadas e colocadas no cérebro dos alunos, construindo alternativas para a educação que envolve primeiramente a participação ativa em comunidades sociais.

Participando das aulas como compositores, intérpretes e audiência crítica, no estudo realizado as crianças construíram sua identidade no grupo e tornaram-se agentes da própria aprendizagem, construindo coletivamente o conhecimento que sustenta as suas ideias de música, constantemente revistas, atualizadas e ampliadas pelas suas experiências musicais e reflexivas. Ao pro- 


\section{Viviane Beineke}

fessor, cabia estabelecer um ambiente de relações sociais positivas, de comprometimento com os processos de aprendizagem do grupo, de colaboração mútua, de engajamento de interesses e de valorização das contribuições das crianças em aula. Ao longo do tempo, essas formas de participação social configuraram a constituição de uma comunidade de prática musical engajada e comprometida no processo de negociação e significação dessas práticas, compartilhando maneiras de fazer e pensar música que sustentam a aprendizagem criativa.

\section{Considerações}

Nos entrelaçamentos da educação musical com os estudos sobre a criatividade, a aprendizagem criativa se apresenta como um desafio aos educadores, no intuito de construir comunidades de prática em sala de aula, em processos significativos de aprendizagem musical. Como salientam Jeffrey e Woods (2009), na aprendizagem criativa o conceito de inovação adquire outro sentido, focalizando a compreensão que os alunos desenvolvem do currículo, da pedagogia e da aprendizagem social.

Destacam-se as transformações nas relações humanas que os alunos vivenciam e ampliam na aprendizagem criativa: uma experiência de igualdade, status, vivacidade com relação aos pares e outras pessoas e um compromisso em ocupar-se mais na aprendizagem social pelo bem que ela proporciona aos participantes. Retomando Craft (2011), aprender criativamente está relacionado também a amplos valores éticos que precisam ser construídos na escola, em processos socialmente participativos e colaborativos. Como argumentam Bitencourt, Pessôa e Silva (2008), o desenvolvimento da capacidade criadora dos alunos através de atividades de composição pode formar pessoas capazes de intervir e transformar a sociedade em que vivem de maneira crítica e consciente, contribuindo para um desenvolvimento mais igualitário, com menos concentração de poder e controle.

Sob a óptica da aprendizagem criativa, as práticas musicais em sala de aula não visam apenas à criação de algo novo para os alunos ou à aplicação de conhecimentos adquiridos, pois mais do que os produtos elaborados em aula, o foco são as aprendizagens colaborativas, de seres humanos que se relacionam fazendo música, que se escutam e que aprendem uns com os outros. Nessa perspectiva, a aprendizagem criativa em música pode indicar uma alternativa possível quando se deseja construir uma educação musical na escola básica que contribua com a formação de pessoas mais sensíveis, solidárias, críticas e transformadoras, quando a criação abre a possibilidade de pensar um mundo melhor. 


\section{Referências}

ALENCAR, E. S. de; FLEITH, D. de S. Criatividade: múltiplas perspectivas. 3. ed. revista e ampliada. Brasília: Editora Universidade de Brasília, 2003.

AMABILE, T. M. Creativity in context. Oxford: Westview Press, 1996.

BARATA-MOURA, J. Da criatividade como trabalho do possível. In: PATRíCIO, M. F. (Org.). Escola, aprendizagem e criatividade. Lisboa: Porto Editora, 2001, p. 137-149.

BARRET, M. S. Freedoms and constraints: constructing musical worlds through the dialogue of composition. In: HICKEY, M. (Ed.). Why and how to teach music composition: a new horizon for Music Education. Reston: MENC - The National Association for Music Education, 2003, p. 3-27.

BEINEKE, V. Processos intersubjetivos na composição musical de crianças: um estudo sobre a aprendizagem criativa. 2009. $289 \mathrm{f}$. Tese (Doutorado em Música) - Universidade Federal do Rio Grande do Sul, Porto Alegre, 2009. Disponível em: <http://hdl.handle.net/10183/17775>

BITENCOURT, R. L.; PESSÔA, P. P.; SILVA, J. A. S. A metodologia de pesquisa-ação em práticas de composição no ensino de música. In: ENCONTRO NACIONAL DA ABEM, 17., 2008, São Paulo. Anais... São Paulo: UNESP, 2008. p. 1-6. 1 CD-ROM.

BODEN, M. A. O que é criatividade? In: BODEN, M. A. (Org.). Dimensões da criatividade. Porto Alegre: Artmed, 1999. p. 81-123.

BURNARD, P. The individual and social worlds of children's musical creativity. In: MCPHERSON, G. (Ed.). The child as musician: a handbook of musical development. Oxford: Oxford University Press, 2006. p. 353-374.

. Investigating children's meaning-making and the emergence of musical interaction in group improvisation. British Journal of Music Education, v. 19, n. 2, p. 157-172, 2002.

CAMPBELL, P. S. Global practices. In: MCPHERSON, Gary (Ed.). The child as musician: a handbook of musical development. Oxford: Oxford University Press, 2006. p. 415-437.

CHENG, V. M Y. Consensual assessment in creative learning. In: CRAFT, A.; CREMIN, T.; BURNARD, P. (Ed.). Creative learning 3-11: and how to document it. Stoke on Trent: Trentham, 2008. p. 163-170.

CRAFT, A. Creativity and Education Futures: Learning in a Digital Age. Stoke on Trent: Trentham, 2011.

2005.

Creativity in Schools: tensions and dilemmas. London: Routledge, 
CRAFT, A. The limits to creativity in education: dilemmas for the educator. British Journal of Educational Studies, v. 51, n. 2, p. 113-127, 2003.

CRAFT, A.; CREMIN, T.; BURNARD, P. Creative learning: an emergent concept. In: CRAFT, A.; CREMIN, T.; BURNARD, P. (Ed.). Creative learning 3-11: and how to document it. Stoke on Trent: Trentham, 2008. p. xix-xxiv.

CSIKSZENTMIHALYI, M. Creativity: flow and the psychology of discovery and invention. New York: Harper Perennial, 1997.

EYSENCK, H. J. As formas de medir a criatividade. In: BODEN, M. A. (Org.). Dimensões da criatividade. Porto Alegre: Artmed, 1999, p. 203-244.

FELDMAN, D. H. Foreword: Documenting creative learning, changing the world. In: CRAFT, A.; CREMIN, T.; BURNARD, P. (Eds.). Creative learning 3-11: and how to document it. Stoke on Trent: Trentham, 2008, p. xiii-xvii.

FONSECA, V. da. A educabilidade cognitiva no século XXI. In: PATRÍCIO, M. F. (Org.). Escola, aprendizagem e criatividade. Lisboa: Porto Editora, 2001, p. 15-26.

GARDNER, H. Os padrões dos criadores. In: BODEN, M. A. (Org.). Dimensões da criatividade. Porto Alegre: Artmed, 1999, p. 149-163.

HICKEY, M. An application of Amabile's Consensual Assessment Technique for rating the creativity of children's musical compositions. Journal of Research in Music Education, v. 49, n. 3, p. 234-244, 2001.

IBÁÑEZ, R. M. El aprendizage creativo en la escuela: El "problem solving". In: PATRÍCIO, M. F. (Org.). Escola, aprendizagem e criatividade. Lisboa: Porto Editora, 2001. p. 123-131.

JEFFREY, B.; WOODS, P. Creative learning in the Primary School. London: Routledge, 2009.

KRATUS, J. The ways children compose. In: LEES, H. (Ed.). Musical Connections: Tradition and Change. Tampa, 1994. p. 128-141.

LUBART, T. Creativity across cultures. In: STERNBERG, R.o J. (Ed.). Handbook of Creativity. 10th printing. Cambridge: Cambridge University Press, 2007a, p. 339-350.

Psicologia da Criatividade. Tradução Márcia Conceição Machado Moraes. Porto Alegre: Artmed, 2007b.

MARSH, K. Children's singing games: composition in the playground? Research Studies in Music Education, v. 4, p. 2-11, 1995.

The musical playground: global tradition and change in children's songs and games. Oxford: Oxford University Press, 2008. 
MATEIRO, T. John Paynter: a música criativa nas escolas. In: MATEIRO, T.; ILARI, B. (Org.). Pedagogias em educação musical. Curitiba: Ibpex, 2011, p. 243-273.

PRIEST, T. Using creativity assessment experience to nurture and predict compositional creativity. Journal of Research in Music Education, v. 49, n. 3 , p. 245-257, 2001.

SAWYER, R. K. Group creativity: musical performance and collaboration. Psychology of Music, n. 34, v. 2, p. 148-165, 2006.

SPENDLOVE, D.; WYSE, D. Creative learning: definitions and barriers. In: CRAFT, A.; CREMIN, T.; BURNARD, P. (Eds.). Creative learning 3-11: and how to document it. Stoke on Trent: Trentham, 2008. p. 11- 18.

ST. JOHN, P. A. Finding and making meaning: young children as musical collaborators. Psychology of Music, v. 34, n. 2, p. 238-261, 2006.

SWANWICK, K. Musical knowledge: intuition, analysis and music education. London: Routledge, 1994.

TAFURI, J. Processes and teaching strategies in musical improvisation with children. In: DELIĖGE, I.; WIGGINS, G. A. (Ed.) Musical Creativity: multidisciplinary research in theory and practice. New York: Psychology Press, 2006. p. 134-157.

WENGER, E. Communities of practice: learning, meaning, and identity. 18th printing. Cambridge: Cambridge University Press, 2008.

YOUNG, S. Time-space structuring in spontaneous play on educational percussion instruments among three- and four-year-olds. British Journal of Music Education, v. 20, n. 1, p. 45-59, 2003.

\footnotetext{
Notas

1 Versão revisada e ampliada da comunicação "Criatividade e educação musical: trajetórias e perspectivas de pesquisa", apresentada no XX Congresso da Associação Nacional de Pesquisa e Pós-Graduação em Música, em Florianópolis (2010).

2 Pesquisa de doutorado realizada no Programa de Pós-Graduação em Música da Universidade Federal do Rio Grande do Sul, sob orientação da Profạ. Drª . Liane Hentschke.

${ }^{3}$ Boden (1999) adverte que a criatividade- $H$ nem sempre é atribuída corretamente aos seus respectivos autores, porque uma ideia que não foi valorizada em certo contexto pode ser tida como "nova" em outro.

${ }^{4}$ No Modelo Sistêmico de Criatividade, Csikszentmihalyi (1997) propõe que a criatividade só pode existir na inter-relação de um sistema composto por três elementos: o domínio, o campo e o indivíduo. O domínio e o campo representam o contexto dentro do qual o indivíduo opera; o componente cultural é o domínio, e o componente social é o campo.

${ }^{5}$ Para comprovar essa ideia, basta entrar numa livraria virtual e buscar a palavra-chave criatividade. Os resultados apontam dezenas de livros, nas mais diversas áreas, propondo "estratégias para turbinar a criatividade", "treinamento da criatividade", "guia para desenvolver
} 


\section{Viviane Beineke}

a criatividade nos negócios", "liderança e criatividade", "criatividade aplicada" ou "como aumentar o poder do cérebro", entre muitos outros.

${ }^{6}$ A TAC foi elaborada com base na concepção de que o contexto social e cultural é fundamental para a compreensão dos produtos criativos, reconhecendo que os especialistas que conhecem e compreendem esse contexto podem avaliar a criatividade (AMABILE, 1996).

${ }^{7}$ Como explica Wenger (2008, p. 4, grifo do autor), a participação numa comunidade de prática não se refere somente à participação em eventos isolados de engajamento em certas atividades, mas "[...] um processo mais abrangente de participar ativamente nas práticas de comunidades sociais e construção de identidades em relação a essas comunidades. Esse tipo de participação configura não só o que fazemos, mas também quem nós somos e como interpretamos o que fazemos".

${ }^{8}$ Uma comunidade de prática, segundo Wenger (2008), caracteriza-se pelo (1) engajamento mútuo entre pessoas envolvidas em ações cujos significados são negociados entre si; (2) articulação empreendedora, que resulta de um processo coletivo de negociação entre os membros da comunidade; e (3) repertório compartilhado entre os participantes, o qual pode incluir rotinas, palavras, ferramentas, formas de fazer as coisas, histórias, gestos, símbolos, ações e conceitos produzidos ou adotados pela comunidade.

${ }^{9} \mathrm{Tal}$ como define Swanwick (1994), neste trabalho entende-se composição de forma bastante ampla, incluindo arranjos e improvisações musicais, ideias musicais criadas pelos alunos com a intenção de expressar pensamentos musicais, com ou sem utilizar notação ou outra forma de registro da composição.

\section{Correspondência}

Viviane Beineke - Rua Europa, 228 apto. 944 Trindade - CEP 88036-135 Florianópolis - Santa Catarina, Brasil.

E-mail: vivibk@gmail.com

Recebido em 01 de setembro de 2011

Aprovado em 21 de outubro de 2011 